\title{
Thermal expansion imaging for monitoring lesion depth using M-mode ultrasound during cardiac RF ablation: in vitro study
}

\author{
Peter Baki $^{1}$ - Sergio J. Sanabria ${ }^{1}$ - Gabor Kosa ${ }^{2}$ - Gabor Szekely ${ }^{1}$ • \\ Orcun Goksel ${ }^{1}$
}

Received: 26 January 2015 / Accepted: 2 April 2015 / Published online: 23 April 2015

(C) CARS 2015

\begin{abstract}
Purpose We demonstrate a novel method for automatic direct lesion depth (LD) tracking during coagulation from time series of a single A-mode ultrasound (US) transducer custom fit at the tip of a RFA catheter. This method is named thermal expansion imaging (TEI).

Methods A total of 35 porcine myocardium samples were ablated (LD 0.5-5 mm) while acquiring US, electrical impedance (EI) and contact force (CF) data. US images are generated in real time in terms of echo intensity (M-mode) and phase (TEI). For TEI, displacements between US time series are estimated with time-domain cross-correlation. A modified least squares strain estimation with temporal and depth smoothing reveals a thermal expansion boundary (TEB) - negative zero-crossing of temporal strain — which is associated to the coagulated tissue front.

Results M-mode does not reliably delineate RFA lesions. TEI images reveal a traceable TEB with RMSE $=0.50 \mathrm{~mm}$ and $R^{2}=0.85$ with respect to visual observations. The conventional technique, EI, shows lower $R^{2}=0.7$ and $>200 \%$
\end{abstract}

Sergio J. Sanabria

ssanabria@ethz.ch

Peter Baki

bakip@ vision.ee.ethz.ch

Gabor Kosa

gkosa@post.tau.ac.il

Gabor Szekely

szekely@ethz.ch

Orcun Goksel

ogoksel@ethz.ch

1 Computer Vision Laboratory, ETH Zurich, Sternwartstrasse 7, 8092 Zurich, Switzerland

2 School of Mechanical Engineering, Faculty of Engineering, Tel Aviv University, 6997801 Tel Aviv, Israel variations with $\mathrm{CF}$. The discontinuous time progression of the TEB is qualitatively associated to tissue heterogeneity and $C F$ variations, which are directly traceable with TEI. The speed of sound, measured in function of tissue temperature, increases up to a plateau at $55^{\circ} \mathrm{C}$, which does not explain the observed strain bands in the TEB.

Conclusions TEI successfully tracks LD in in vitro experiments based on a single US transducer and is robust to catheter/tissue contact, ablation time and even tissue heterogeneity. The presence of a TEB suggests thermal expansion as the main strain mechanism during coagulation, accompanied by compression of the adjacent non-ablated tissue. The isolation of thermally induced displacements from in vivo motion is a matter of future research. TEI is potentially applicable to other treatments such as percutaneous RFA of liver and high-intensity focused ultrasound.

Keywords Ultrasound - Strain imaging - Lesion control · Radio-frequency ablation

\section{Introduction}

Cardiac arrhythmia is any of the conditions of irregular electrical heart activity. The sinoatrial (SA) node is the natural pacemaker of the heart located in the right atrium, initiating electrical impulses that propagate and slow down through the atrioventricular (AV) node and trigger cardiac muscle contraction in atria and ventricles at appropriate times (Fig. 1). Arrhythmic impulses are initiated by ectopic foci-cardiac cells triggered asynchronously or recurrently. Fibrillation occurs when an entire chamber of the heart is affected by multiple reentry circuits [1]. Atrial fibrillation (AF) is the most common atrial arrhythmia and among the fastest growing 

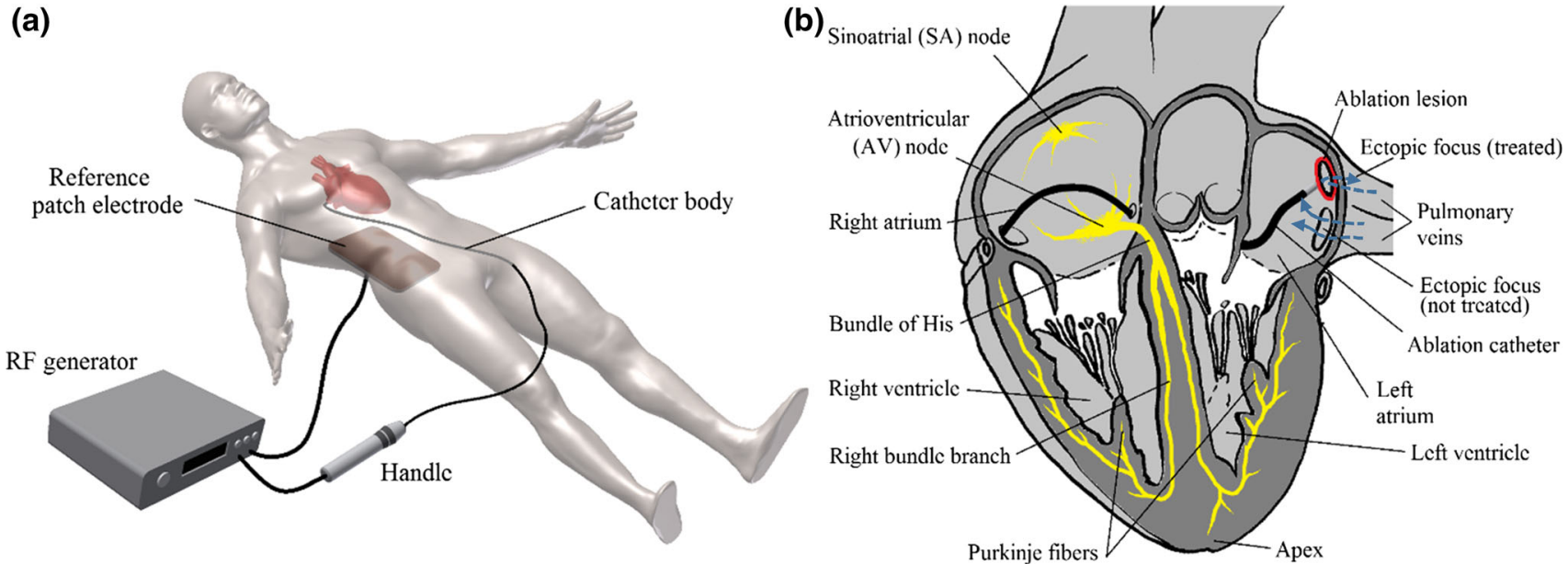

Fig. 1 a Radiofrequency ablation (RFA) setup. b Cross-sectional view of human heart with electrical impulse transmission system. RFA treatment of ectopic foci inducing atrial fibrillation (AF) is illustrated

diseases, affecting $15 \%$ of patients older than 70 years, with a five times higher chance of stroke than normal sinus rhythm and twofold risk of mortality $[2,3]$.

Radiofrequency catheter ablation (RFA) is an interventional treatment of choice for a number of heart arrhythmia [4]. RFA induces localized thermal lesions in the myocardium to block arrhythmic conduction paths. A catheter is inserted into a vein (typically in the groin or the neck) and its tip is wire steered within the heart chamber (Fig. 1a). For instance, the typical firing of ectopic foci in $\mathrm{AF}$ is found around the pulmonary veins and can be isolated with RFA [5] (Fig. 1b). During unipolar RFA, circulation of unmodulated sine wave RF current $(300-500 \mathrm{kHz})$ between the catheter tip and a large patch electrode applied to the patient's skin results in a focal heating and tissue necrosis due to protein coagulation. The RFA power delivery period takes typically $30-60 \mathrm{~s}$ creating lesions of $5-6 \mathrm{~mm}$ in diameter and $2-3 \mathrm{~mm}$ in depth [6]. Irreversible conduction blocks occur at tissue locations exceeding a temperature of $50^{\circ} \mathrm{C}$ [7]. Too high tissue temperatures, however, may lead to tissue charring $\left(80^{\circ} \mathrm{C}\right)$ and water steaming $\left(100^{\circ} \mathrm{C}\right)$, increasing the risk of thromboembolic complications or cardiac perforations, respectively $[4,8]$. Insufficient power delivery, on the other hand, will lead to lesion "reconnection" and "recovery," resulting in procedural failure and arrhythmia recurrence $[9,10]$. A real-time intra-operative lesion assessment is therefore necessary to minimize intervention time, monitor complications and ensure therapy success.

The success of RFA is often related to the identification of arrhythmia's site of origin and the stabilization of the catheter tip at this point, which can be achieved with cardiac mapping of electrical activity, and non-invasive catheter guidance (X-ray CT, MRI, ICE, magnetic navigation) [11]. Another important-however less explored-issue is determining precisely the dimensions of the lesion induced by the ablation procedure. Lesion gaps and lack of transmurality are directly associated to arrhythmia recurrence $[9,10,12]$. Commercial RFA catheters integrate electrode-tissue interface temperature monitoring, together with indirect measurements of lesion size (e.g., through surface electrical impedance EI and contact force CF). However, electrical impedance (EI) is in vivo affected by cavitary blood flow, coagulum on the tip and electrode orientation, therefore not providing a precise feedback [13]. These factors also complicate the estimation of inner tissue temperature from interface temperature [14-16]. Contact force (CF) control may be an alternative as contact quality and duration of the treatment have proven to correlate well with lesion dimensions $[13,17,18]$. Some novel endoscopic catheter designs allow for direct real-time visualization of scar tissue on the myocardium surface [19], but are not appropriate for measuring lesion depth. MRI may be an alternative to non-invasively visualizing gaps in ablation lesions or tissue heating, but suffers from poor spatial resolution $(<2 \mathrm{~mm})$ and low frame rate ( $<5$ FPS $)$ apart from high costs and potential equipment incompatibility with RFA [20,21].

Ultrasound (US) imaging is a powerful medical diagnostic modality which allows for in vivo, hazard-free and real-time imaging of human tissue [22]. Conventional sonography emits a pulsed US signal through tissue and records a time trace (A-mode) of the reflected US echoes, which is used to identify echogenic structures as a function of depth. M-mode acquisition repeats this procedure for a sequence of time instances, which is useful to monitor dynamic processes, such as RFA ablation. However, several authors hold the view that sonography alone is inadequate to identify necrotic tissue as the echogenicity does not significantly change during thermal therapy [23-26]. Decorrelation in M-mode images that occurs due to microbubble formation caused by cavitation or boiling has been proposed to monitor ablation [27]; however, this correlates poorly with RFA lesion propagation [28]. 
Recently, an ultrasound array was integrated in an irrigated RFA catheter [29], and, by means of US focusing and data filtering, sufficient contrast was achieved in M-mode images to estimate the depth of tissue necrosis (coefficient of determination $R^{2}=0.62$ ). US elastography aims at measuring the elastic properties of soft tissue by using correlation-based methods to track changes in the tissue structure as a response to mechanical excitation, which are coded in the phase of the US signals. Separate RFA catheters and US arrays were used in [30] with acoustic radiation force impulse (ARFI) elastography to image RFA lesion geometry as a stiff inclusion and to automatically estimate 2D lesion size after ablation (1-2 mm uncertainty).

Thermal strain imaging (TSI) tracks strain changes in the tissue structure as a result of temperature changes [31]. The temperature dependence of the ultrasound echo is caused by thermal expansion of the propagating medium and variation of sound speed due to changes in temperature. By considering the sound speed variations, tissue temperature maps prior to coagulation are obtained [31-33]. However, real-time lesion size assessment during coagulation is a less investigated area. [34] integrated an ultrasound array within an irrigated RFA catheter and generated 2D thermal strain images by correlating successive US frames. The change in the slope of thermally induced strain with temperature in myocardial tissue was linked to a plateau in the speed of sound curve upon coagulation. [35] used a 2D array transducer to obtain echo-strain images during highintensity focused ultrasound (HIFU) ablation of porcine liver and manually identified a high-strain region, the boundary of which subsequently correlated with visual lesion size $\left(R^{2}=0.9\right)$ and was associated to tissue expansion during coagulation. To our knowledge, this latter concept has neither been applied to RFA nor integrated within an ablation catheter.

In this work, we describe an RFA catheter composed of a single US sensor integrated within the ablation tip, and a method (thermal expansion imaging, TEI) that delineates $\mathrm{RF}$ ablation lesion depth during coagulation from an apparent high-strain band observed by processing M-mode US time series. In comparison with the aforementioned catheter designs [29,34], which incorporate multiple sensor arrays, the driving and data acquisition of a single transducer does not require complex hardware. Moreover, the US sensing is easily integrated with other sensors (e.g., contact force CF, electrical impedance EI) in a multi-functional catheter tip. Similarly to TSI imaging and [35], the TEI method is based on the detection of strain variations during coagulation. However, the identification of the lesion size is performed in a fully automatic way. An in vitro RFA study is presented on porcine heart samples to demonstrate the feasibility of TEI and its complementarity to CF and EI measurements. Further insight into the impact of tissue coagulation in the US signal is gained with additional US speed of sound measurements for a range of homogeneous tissue temperatures.

\section{Materials and methods}

\section{RFA and ultrasound setup}

An unipolar RF ablation system was developed (Fig. 2a), which incorporates in a single tool RF ablation, ultrasound (US) imaging and contact force (CF) sensing. The RFA system also allows for temperature measurement with a separate type-K thermocouple. It as well monitors the electrical impedance (EI) between catheter tip and patch electrode. The CF sensors base on a novel miniature (3-4 mm diameter) triaxial force sensor concept for minimally invasive surgery (MIS). They consist of piezo-resistive strain gauges mounted on a precision-machined titanium alloy body and detect forces between 0 and $2 \mathrm{~N}$ with $5 \mathrm{mN}$ resolution and $\pm 1^{\circ}$ angle accuracy $[36,37]$. The RFA is performed at $500 \mathrm{kHz}$ in pulse width modulation (PWM) power control mode (Fig. 2c), with a maximum power delivery of $30 \mathrm{~W}$. The system operates at $200 \mathrm{~V}$ AC with a nominal impedance of $100 \Omega$, which approximates the catheter-endocardial contact [38]. A switching frequency of $20 \mathrm{~Hz}$ (period $50 \mathrm{~ms}$ ) is found appropriate for the slow thermodynamics of tissue [39]. To avoid electrical interference, ultrasound data are acquired with the ablation switched off, which requires $10 \mathrm{~ms}$ of the ablation cycle for US sampling and communication. A LabVIEW virtual instrument enabled by a footswitch pedal is used to start and stop the ablation process and to synchronously acquire and visualize sensor data.

Figure $2 \mathrm{~b}$ shows the custom-designed catheter head. The RF ablation electrode consists of a $3.2 \mathrm{~mm}$ diameter tubeshaped stainless steel cap, which is slightly bent at its termination to increase contact area. A tailor-made single element US transducer (Vermon, Tours, France) with dimensions $5 \mathrm{~mm} \times 2 \mathrm{~mm}$ fits the opening of the ablation electrode with a $0.1-\mathrm{mm}$ gap. The contact surface of the US probe and the electrode opening is on the same plane, which removes the need of a coupling medium between tissue and US transducer. This is an advantage with respect to more complex US array/catheter designs, which typically require US gel [34] or irrigated water [40] as coupling media. The US transducer is a conventional $20 \mathrm{MHz}$ piezoelectric element and is driven by negative square pulses with an amplitude of $50 \mathrm{~V}$ and $25 \mathrm{~ns}$ duration generated by an USBox ultrasound pulser/receiver (LeCoeur Electronique, Chuelles, France). The received US echo time series (A-scans) are amplified by $35 \mathrm{~dB}$ with a low-noise unit (Olympus 5073 PR, Waltham, MA, USA) and digitized by the USBox in function of time with $80 \mathrm{MHz}$ sampling frequency and 12 bit resolution. 
(a)

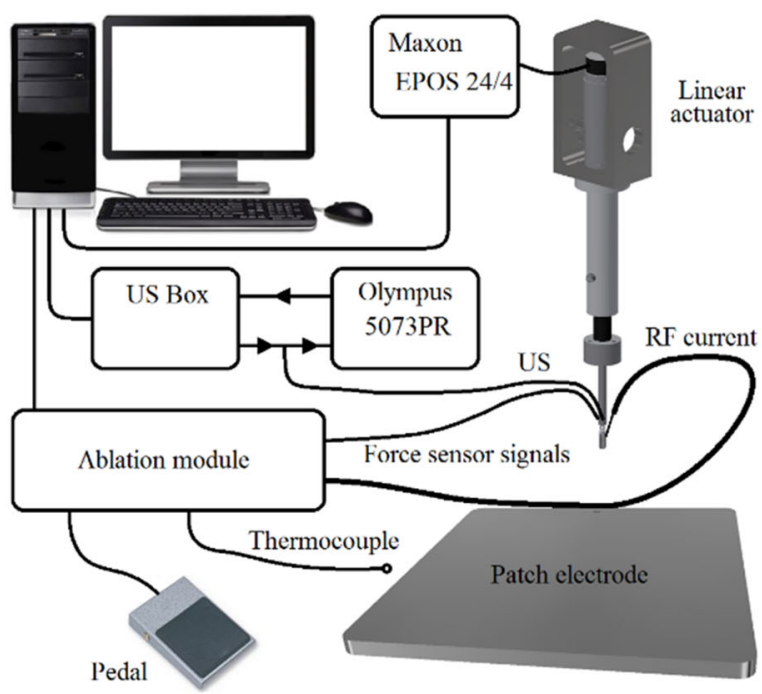

(c)

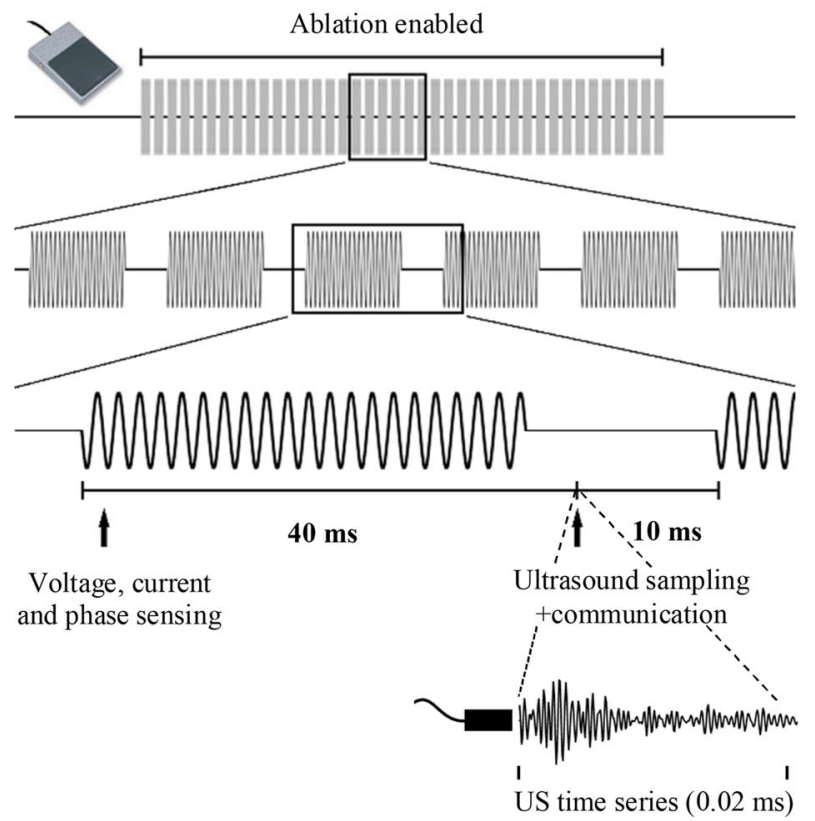

(b)
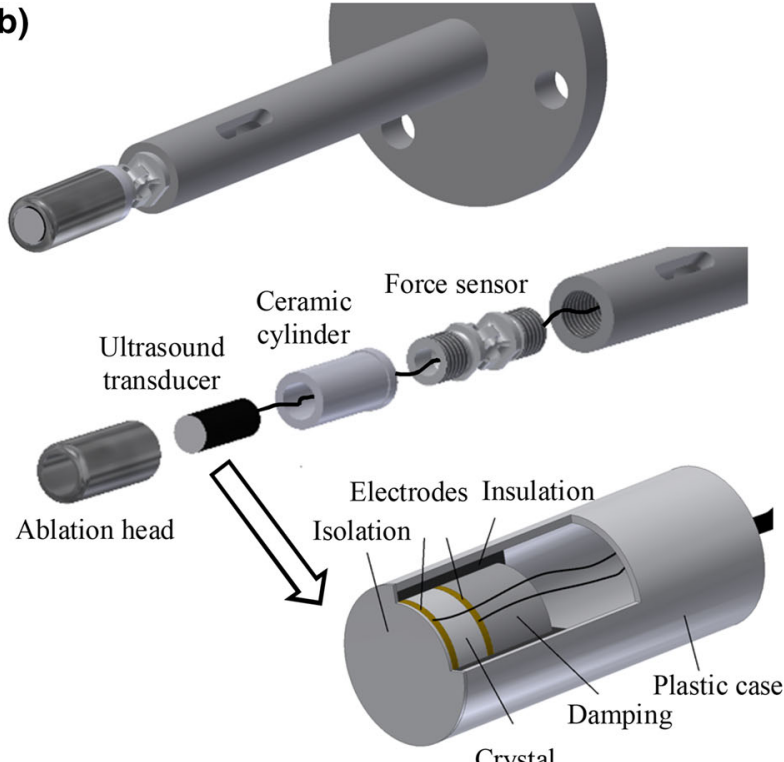

(d)

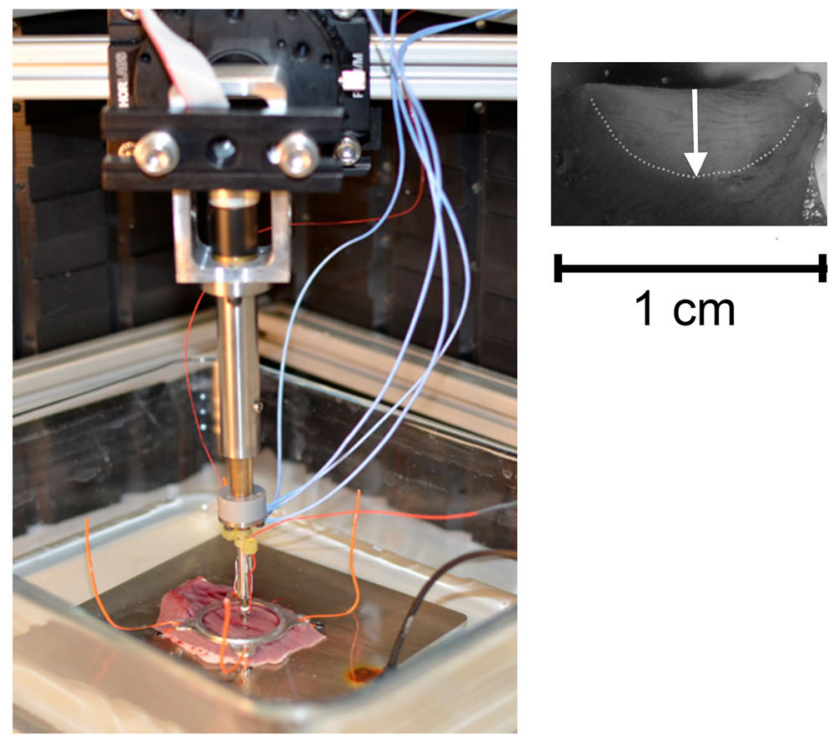

Fig. 2 a RFA system with sensor feedback. b Exploded an assembled CAD model of catheter head components. c Sampling and communication system during ablation, including US sensor readout. d In vitro study on porcine heart myocardium samples. Visually assessed lesion depth

Since the US measurement is carried out with the RF electrode turned off, the US data readout is decoupled from the ablation parameters used.

\section{In vitro experiments}

For in vitro ablation experiments, $4 \times 4 \mathrm{~cm}^{2}$ samples $(N=$ 35 ) of porcine hearts from a local slaughterhouse (Zurich) were positioned on a stainless steel patch and immersed in $0.9 \%$ saline solution at $25^{\circ} \mathrm{C}$ (Fig. 2d). Myocardium thickness among the samples varied from 0.5 to $1.3 \mathrm{~cm}$. $\mathrm{RF}$ ablations were performed at $12.5 \mathrm{~W}$ power for intervals between 10 and $100 \mathrm{~s}$, while simultaneously acquiring ultrasound, electrical impedance and contact force data. After ablation, the samples were incised with a sharp scalpel across the ablation plane, pressed gently against a glass plate and photographed with a tightly focused high-resolution camera. The ablated region was visually identified, based on tissue discoloration, and the lesion depth was manually marked as shown in Fig. 2d. The optical images were evaluated blindly from the ultrasound imaging results. The experiments were 
performed in three test series, for which the influence of the stabilization of contact force $(\mathrm{CF})$ in lesion size reproducibility was analyzed:

(i) With undefined contact force (CF sensor not mounted on catheter) and a given ablation time of around $60 \mathrm{~s}$ $(N=13)$.

(ii) With defined $0.4 \mathrm{~N}$ contact force at ablation times $20 \mathrm{~s}$ $(N=3), 40 \mathrm{~s}(N=3), 60 \mathrm{~s}(N=3), 80 \mathrm{~s}(N=3)$ and $100 \mathrm{~s}(N=2)$, in total $N=14$.

(iii) With defined $0.04 \mathrm{~N}$ contact force at ablation times $20 \mathrm{~s}$ $(N=2), 40 \mathrm{~s}(N=1), 60 \mathrm{~s}(N=1), 80 \mathrm{~s}(N=3)$ and $100 \mathrm{~s}(N=1)$, in total $N=8$.

An additional sample (iv) was used for speed of sound measurements.

\section{Ultrasound imaging of ablation lesions: thermal expansion imaging}

Figure 3 illustrates the main image processing steps applied to track lesion depth from US data. First, conventional processing steps were applied to the digitized US time series (Fig. 3a) to obtain an enhanced visualization or Mmode of echogenic tissue structures (Fig. 3b) [22]. Baseband echo intensity plots were obtained by calculating the Hilbert transform (envelope) of the US time series. The amplitude decrease in function of depth due to tissue attenuation was compensated for with time-gain control. The resulting signal was then normalized and represented in a compressed logarithmic scale. Additional state-of-the-art speckle noise reduction filters were applied (Amplio SDK, Sonix Touch, Analogic Ultrasound, Peabody, MA, USA).

Next, the phase information in the US time series was extracted to obtain the instantaneous displacement between consecutive lines. The phase variations are visible as curved bands in Fig. 3a, b and correspond to tissue structures that displace during ablation due to speed of sound variations and thermal expansion. The displacements $u$ are tracked with time-domain cross-correlation (Eq 1): ing tracking, changes in tissue microstructure are expected to occur due to tissue necrosis, instantaneous displacements are estimated between consecutive US lines, instead of with an initial echo frame in order to avoid correlation tracking loss. The $80 \mathrm{MHz}$ sampling corresponds to a spatial sample size of $\sim 10 \mu \mathrm{m}$. To ensure a robust correlation $\left(R^{2}>0.8\right)$ through most of the signal, a block length $W$ of $600 \mu \mathrm{m}$ with $150 \mu \mathrm{m}$ steps was used (75\% overlap). Due to the small tissue displacements (1-2 samples, Fig. 3c), prior estimates were not necessary, which improved robustness. A relatively large search window $K(125 \mu \mathrm{m})$ allowed for identifying and filtering out poor correlation estimates (too large or discontinuous displacements).

The instantaneous strain $\varepsilon=\partial u / \partial x$ (Fig. 3d) was calculated from the displacement images with a custom extension of the least squares estimator (LSE) of [41] for TEI. Our formulation does not only incorporate displacements from adjacent tissue depths $i$, but as well from adjacent time lines $n$, which reduces strain noise by temporal smoothing (Eq. 2):

$\varepsilon\left(i^{\prime}, n\right)=\frac{\sum_{n \in \mathbf{N}} \sum_{i \in \mathbf{I}} \hat{i} \sum_{n \in \mathbf{N}} \sum_{i \in \mathbf{I}} \hat{u}_{i}-S_{w} \sum_{n \in \mathbf{N}} \sum_{i \in \mathbf{I}} \hat{u}_{i} i}{\left(\sum_{n \in \mathbf{N}} \sum_{i \in \mathbf{I}} \hat{i}\right)^{2}-S_{w} \sum_{n \in \mathbf{N}} \sum_{i \in \mathbf{I}}(i)^{2} w_{i}^{2}}$

$\hat{i}=i w_{i}^{2} \quad \hat{u}_{i}=u_{i} w_{i}^{2} \quad S_{w}=\sum_{n \in \mathbf{N}} \sum_{i \in \mathbf{I}} w_{i}^{2}$

$\mathbf{N}=\left[n-K_{N} / 2, n+K_{N} / 2\right]$

$\mathbf{I}=\left[i-\left\lfloor K_{I} i / I\right\rfloor, i-\left\lfloor K_{I} i / I\right\rfloor+K_{I}\right]$

$i^{\prime}=0.5 \cdot[\mathbf{I}(2)+\mathbf{I}(1)]$

This approach is more robust than a standard LSE estimation followed by temporal smoothing of the strain images, for which noisy $u$ values might lead to unbounded $\varepsilon$. Moreover, it provides better lateral resolution for the same kernel size. Poor $u$ estimates are simply not included in the sums. The weighting function $w_{i}$ allows us to assign a stronger weight to displacement values close to the strain calculation depth. However, in this study, a rectangular window $w_{i}=1$ performed similar to a Gaussian $w_{i, n}=$ $\exp \left[-\left(\left(2 / K_{I} i\right)^{2}+\left(2 / K_{N} n\right)^{2}\right) \kappa\right]$ of equivalent width. The

$$
\begin{aligned}
& u(i, n)=\underset{k}{\arg \max } c_{y(n), y(n+1)}(i, k) \\
& c_{y 1, y 2}(i, k) \\
& \quad= \begin{cases}\sum_{w=-W / 2}^{W / 2-k}\left(y_{2}(w-i+k)-\overline{y_{2}}\right)\left(y_{1}(w-i)-\overline{y_{1}}\right) & k=0,1,2 \ldots, K \\
\sum_{w=-W / 2}^{W / 2+k}\left(y_{1}(w-i-k)-\overline{y_{1}}\right)\left(y_{2}(w-i)-\overline{y_{2}}\right) & k=0,-1,-2 \ldots,-K\end{cases}
\end{aligned}
$$

where $i$ and $n$ are, respectively, the calculated sample indexes corresponding to tissue depth $x$ and ablation time $t$. Since dur- calculated $i^{\prime}$ grid is not homogeneous in order to avoid edge artifacts at small tissue depths. In this study, kernel sizes of 


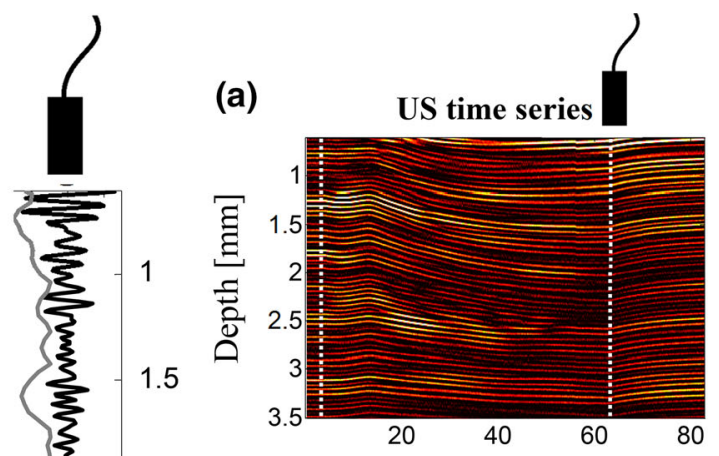

(b) Instantaneous displacement (px)

2 (c)

(c) M-scan
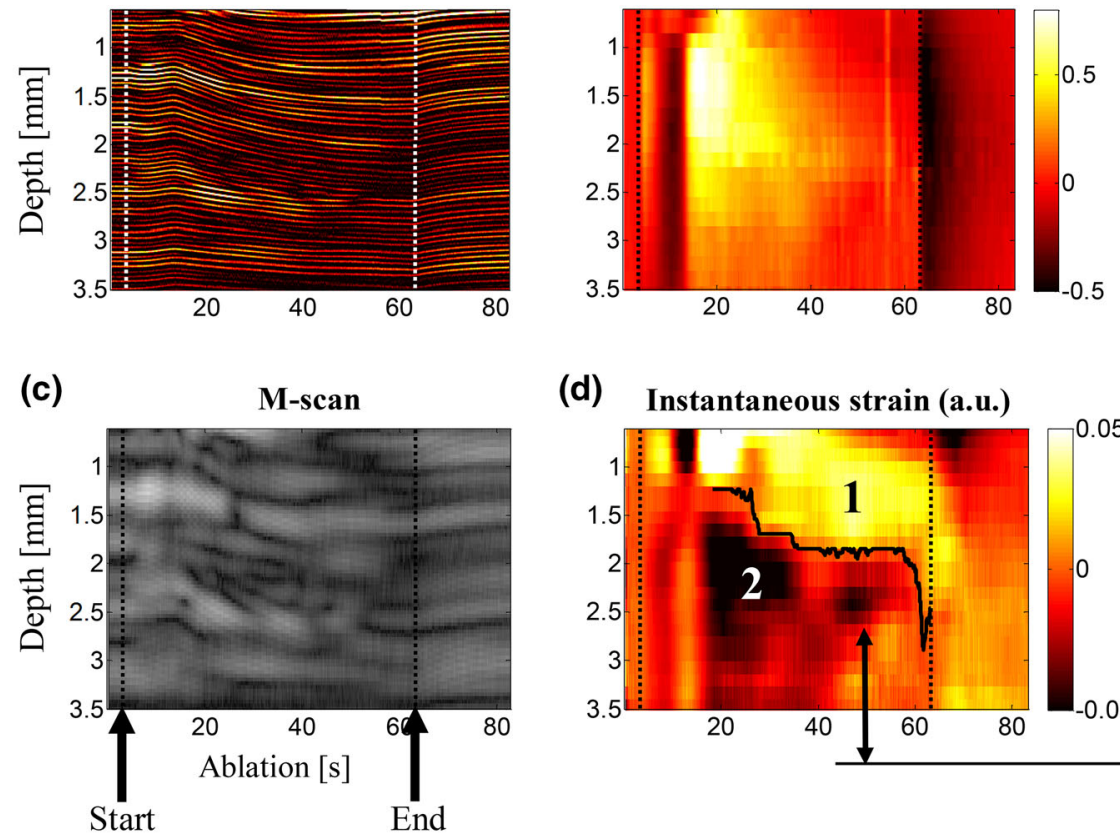

(d) Instantaneous strain (a.u.)

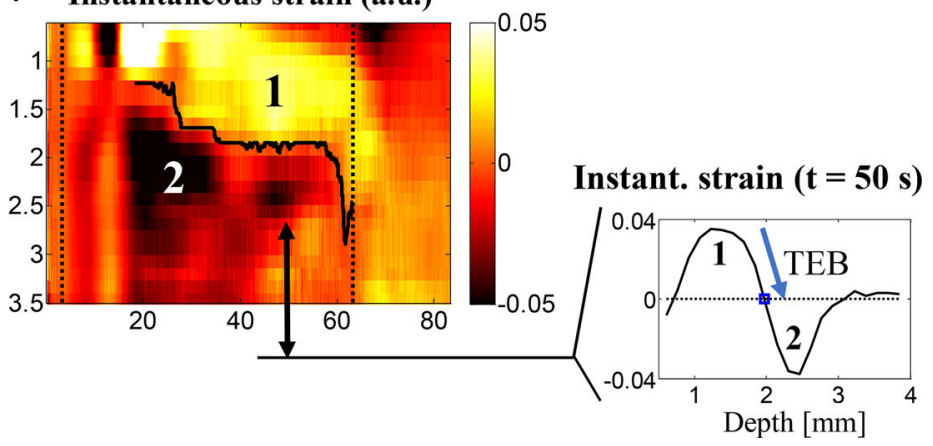

Fig. 3 Data evaluation. Acquired US time series are shown, together with calculated M-scan, instantaneous displacement and strain images. The identification of the thermal expansion boundary (TEB) is also detailed. The results correspond to sample \#5 in Figs. 5 , 6 and 7

$K_{I}=0.9 \mathrm{~mm}$ and $K_{N}=2.5 \mathrm{~s}$ were sufficient for robust tissue depth tracking. The strain images (Fig. 3d) reveal a high-positive-strain band or thermal expansion boundary (TEB), which is empirically associated to the coagulating tissue front. The first negative zero-crossing of the TEB is hypothesized as the ablation boundary and tracked in function of ablation time. A linear fit of $K_{N}$ previous instants is used to estimate the actual lesion size. The residuals provide an automatic way of detecting a discontinuous or noisy TEB.

Both the displacement and strain tracking are based on low-order linear estimates (depth kernel: 50 samples, time kernel: 60 samples), which allow for straightforward realtime implementation of the lesion depth assessment. Even in our currently not optimized Matlab ${ }^{\circledR}$ code, which runs on a single core of an Intel ${ }^{\circledR}$ Core $^{\mathrm{TM}} \mathrm{i7-4770K}$ CPU, a runtime $<20 \mathrm{~ms}$ was achieved per frame, which already provides real-time implementation with respect to the frame acquisition rate $(20 \mathrm{~Hz})$. A $0.02 \mathrm{~ms}$ US time series digitized at $80 \mathrm{MHz} / 16$ bits requires $3.1 \mathrm{kB}$ of data, which leads to a data flow of only $500 \mathrm{kbps}$. Therefore, TEI imaging can be easily implemented in a low-end computing platform, being suitable for handheld devices.

\section{Speed of sound measurements}

Additional US measurements were conducted to characterize the sound speed changes during homogeneous tissue heating in a water bath (Fig. 4). To achieve a rapid temperature transfer from tissue to water, the samples were fixed on an aluminum heat sink. A small fan circulated water while two sinking boilers $(150 \mathrm{~W}$ each) raised the temperature from 14 to $75^{\circ} \mathrm{C}$ in $28 \mathrm{~min}$. The speed of sound $c=2 d_{R} / t_{R}$ was obtained by measuring the time of propagation $t_{R}$ of the ultrasound echo reflected from the flat metal heat sinks. A distance reference was calibrated by bringing the catheter in contact with the heat sink. After fixing the tissue sample on the heat sink (thickness $d_{R}$ ), a small contact force was set $(0.05 \mathrm{~N})$. The temperature was collected as close as possible to the US beam without corrupting the US propagation path. For a constant $d_{R}$, the change of $c$ with temperature results in an echo shift. The time of peak echo amplitude $t_{R}$ is identified and refined with polynomial fitting.

Similarly, speed of sound measurements were performed during in vitro ablation experiments (inhomogeneous tissue heating). A similar reflector configuration with respect to the patch electrode (Fig. 2a) allows for monitoring the effective speed of sound through tissue during ablation.

\section{Results and discussion}

\section{Comparison of M-mode and TEI images of in vitro ablated porcine myocardium}

Figure 5 shows optical images acquired after 13 different RFA experiments. The ablation time was $\sim 60 \mathrm{~s}$, and no con- 

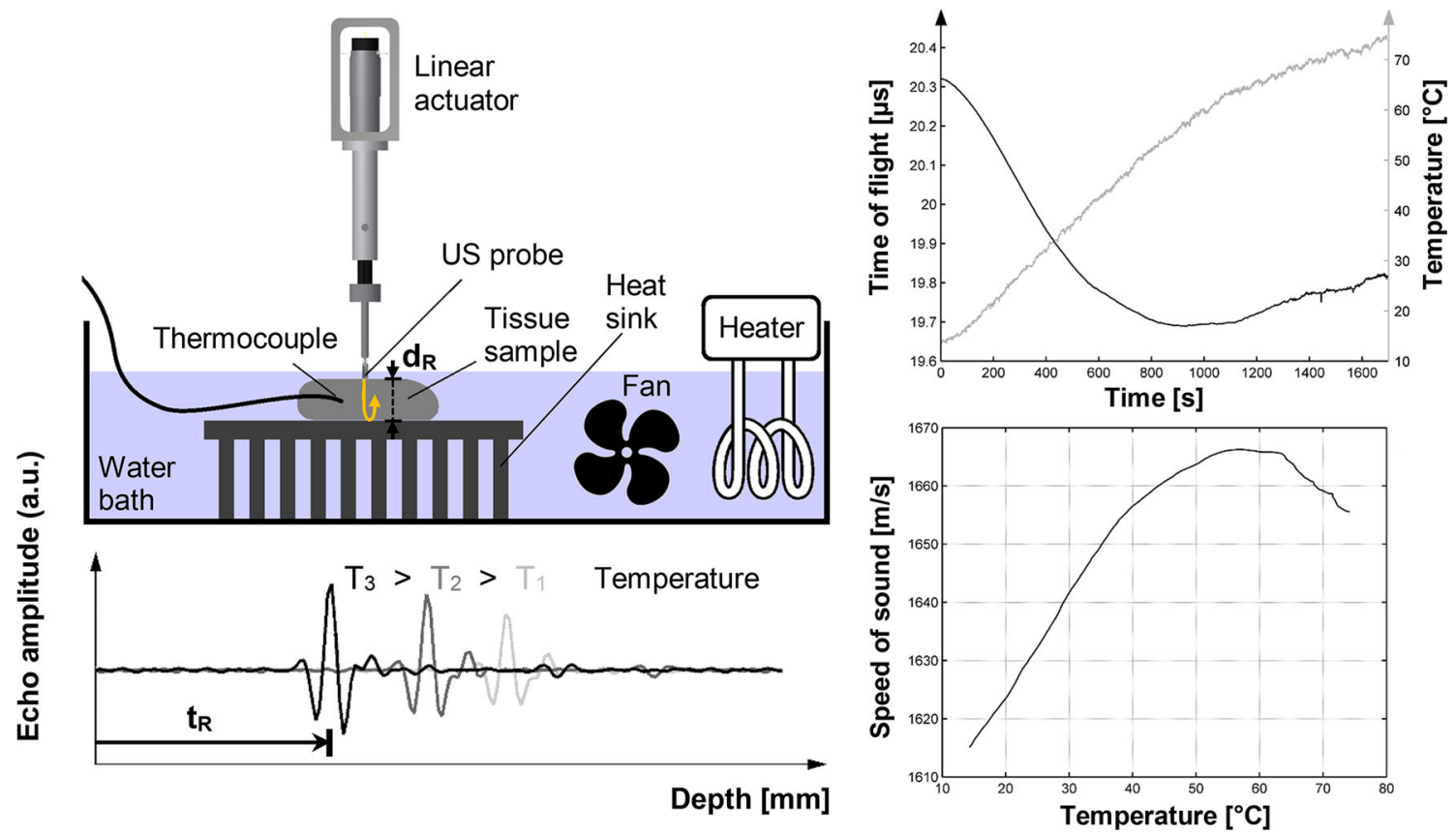

Fig. 4 Speed of sound measurements in homogeneously heated tissue

tact force CF control was applied, which led to significant variations $(0.5 \ldots 3.3 \mathrm{~mm})$ in the visually identified ablation

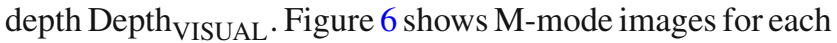
of these experiments. A first observation is that M-mode images cannot be reliably used to assess the coagulated tissue front. Echogenic features were only observed in samples \#2 and \#13; however, these were already present before the start of the ablation process and are probably associated to heterogenic myocardial structures, such as the fibrous connective tissue between cardiac muscle bundles [42], which are visually observable in the incised samples. A careful observation of the M-scans shows a strong phase distortion band due to the coagulation process (clearly visible in \#6 for $t>20 \mu \mathrm{s}$ ). Using adequate smoothing filters, this area could be potentially extracted from the M-scan as an apparent low-echogenicity band, due to phase cancellation. However, it is evident that the main effect introduced by the coagulating tissue is not an echo intensity change, but a phase variation, which is therefore optimally extracted by tracking displacements from the US time series. These observations agree with a large body of the literature [23-26] and provide a possible explanation for the few observations reporting ablation lesion visibility in echo intensity images [29].

The TEI scans (Fig. 7), however, have reproducibly revealed a traceable thermal expansion boundary (TEB), which shows a good agreement with the visually determined lesion depth. The TEB does not always progress smoothly but frequently exhibits a stepwise behavior (for instance \#5, $\# 6$, \#7, \#8, \#9, \#13). We believe that due to the connective tissue lining the inner heart and the different bundles of the heart muscle, the ablation front advances at different speeds within each such layer, while encountering high-resistance gradients between layers. For instance, sample \#2 shows a highly echogenic layer at depth $1.6 \mathrm{~mm}$, which is visible in the M-mode image (Fig. 6). This interface slows down the progress of the ablation front, leading to a plateau in the TEB (Fig. 7, \#2), with respect to other samples (e.g., $\# 6$, \#7, \#8, \#9), for which such a dominating interface is not present; a similar interface and corresponding plateau are also observed in sample \#13. Similarly, although samples \#2-\#13 were ablated for the same time period, strong lesion depth variations are observed. Indeed, some lesions may be unexpectedly shallow (\#3, \#4), potentially due to poor catheter contact or a different tissue layering at the point of contact. For in vivo heart ablation, the convection cooling in blood vessels may complicate such depth-dependent front-propagation speed even more, thereby emphasizing the need for direct imaging methods like ours to monitor lesion depth.

\section{TEI estimation of ablation lesion depth}

With the current processing, TEI achieves a root-meansquare error (RMSE) of $0.5 \mathrm{~mm}$ and a coefficient of determination of $R^{2}=0.85$ (Fig. 8a) in the US estimated lesion depth values Depth US $_{\text {(Fig. 7) with respect }}$

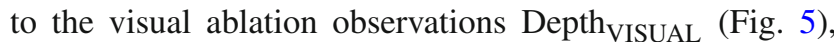
which are taken as the ground truth. The main tradeoff is between TEB contrast and resolution according to 

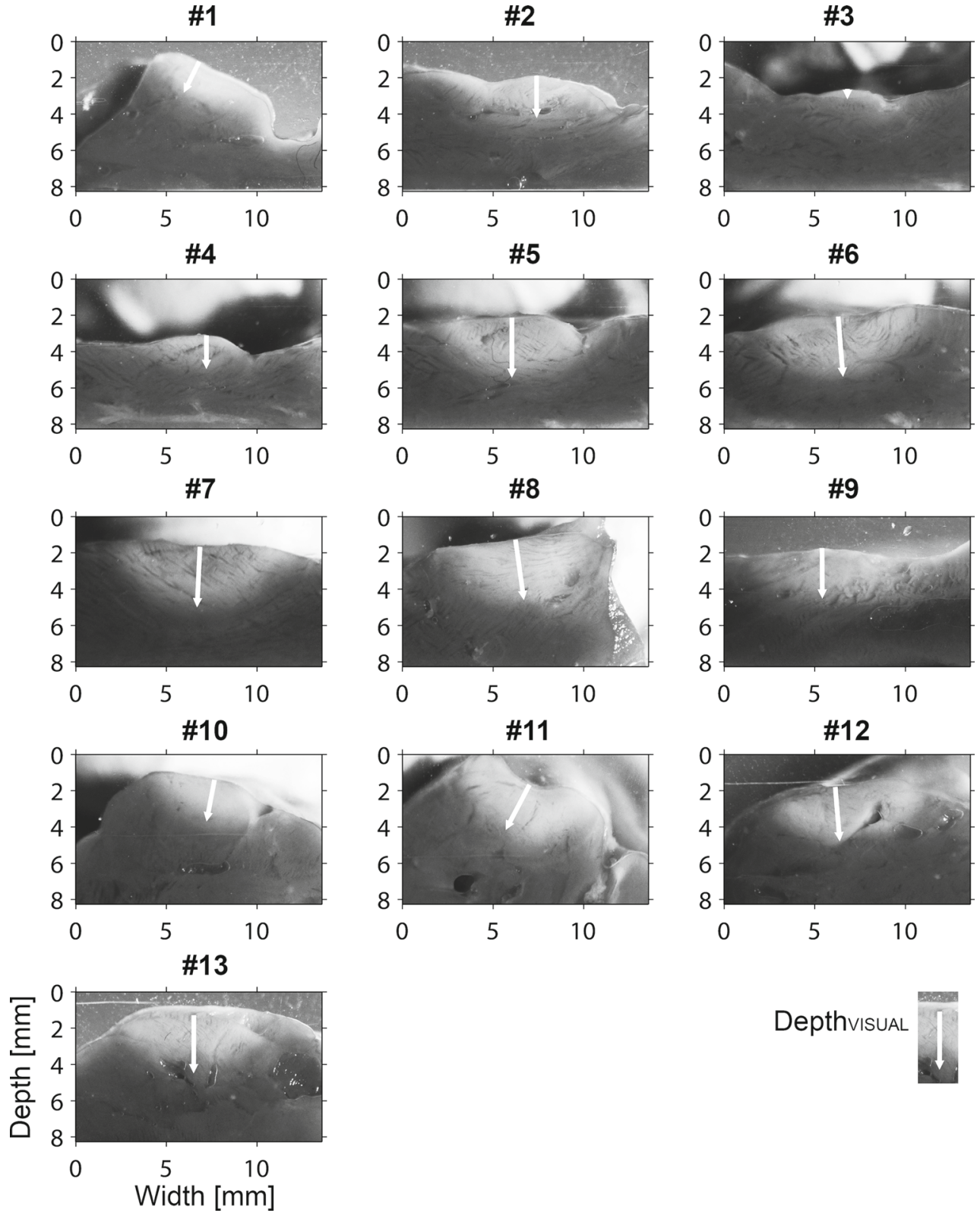

Fig. 5 Tissue optical images acquired after 13 different ablation experiments (ablation time $\sim 60$ s, no contact force CF control). The visually identified lesion depths are marked with arrows

the applied strain estimation kernels. The visual lesion depth uncertainties are associated to the visual identification of the TEB based on tissue discoloration and the potential tissue deformation during incision and are estimated to be $<0.5 \mathrm{~mm}$, in particular within the ablated area since stiffer ablated tissue yields little deformation. TOF mapping to a tissue depth depends on the temperaturedependent speed of sound (SOS). Considering the SOS variation range $\left(<50 \mathrm{~m} \mathrm{~s}^{-1}\right)$ (Fig. 4), the depth uncertainty is then $<3 \%$, well-below the RMSE uncertainties in the visual lesion depth assessment, and therefore negligible.
The stabilization of the contact force (CF) improves the lesion size reproducibility given the ablation time, in agreement with $[13,17,18]$. In comparison with the large Depth $_{\text {visual }}$ variations observed in Fig. 5, given a controlled $\mathrm{CF}=0.4 \mathrm{~N}$ the Depth $_{\text {visual }}$ values for the same ablation times $(20,40 \ldots 100$ s) are seen to lie close to each other (Fig. 8b). This reproducibility worsens for deeper RFA lesions, probably due to a stronger influence of the tissue heterogeneity, as discussed above.

The electrical impedance (EI) consistently shows lower $R^{2}$ regression than TEI (Fig. 8c), the magnitude decrement $\left(R^{2}=0.72\right)$ performing better than the phase decrement 

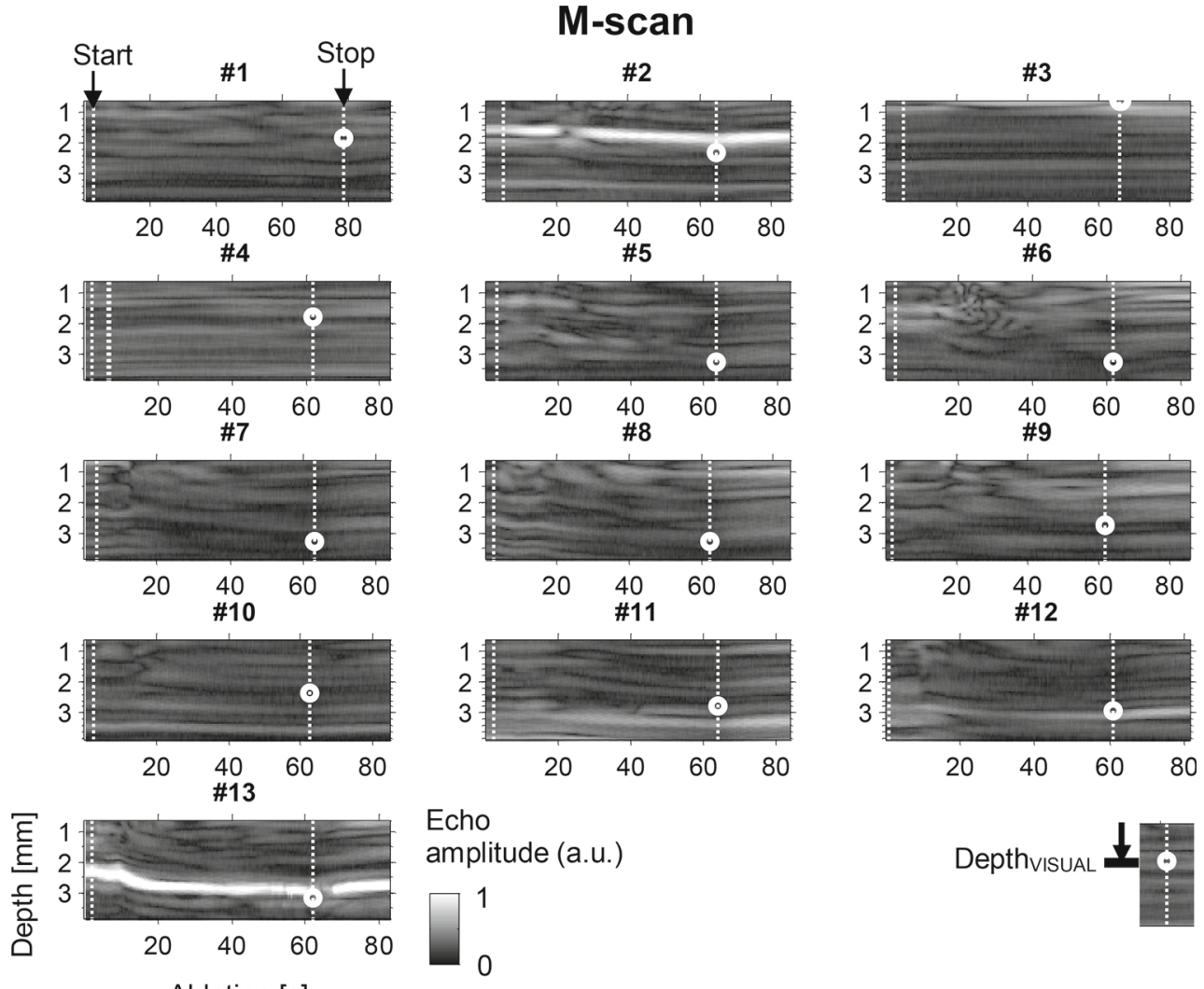

Ablation [s]

Fig. 6 M-scan images for the experiments of Fig. 5. The visually identified ablation depths are plotted on the images

$\left(R^{2}=0.59\right)$ at $\mathrm{CF}=0.4 \mathrm{~N}$. Additionally, EI is highly dependent on CF. For instance, with $\mathrm{CF}=0.04 \mathrm{~N}$, the EI magnitude varies by $200 \%$. Therefore, $R^{2}$ drops to $R^{2}<0.01$ for EI magnitude and $R^{2}<0.35$ for EI phase if $\mathrm{CF}=0.4 \mathrm{~N}$ and $\mathrm{CF}=0.04 \mathrm{~N}$ data are plotted together. In contrast, our TEIestimated lesion depth is seen not to be influenced by $\mathrm{CF}$, with RMSE $=0.46$ for $\mathrm{CF}=0.4 \mathrm{~N}$ (Fig. 8b). This is furthermore almost equivalent to RMSE $=0.50$ if all Depth $_{\mathrm{US}}$ data are plotted together (Fig. 8a), which indicates that TEI is highly robust to $\mathrm{CF}$, to ablation time, and even to tissue heterogeneity to a large extent.

The TEI method is therefore complementary to other control measurements, such as electrical impedance (EI) or contact force $(\mathrm{CF})$ measurements. In our study, $\mathrm{CF}$ regulation significantly improved the reproducibility of lesion depth for the same ablation duration for lesions $<3 \mathrm{~mm}$ deep, however, for larger lesion depths, the repeatability worsens. Electrical impedance (EI) was highly dependent on $\mathrm{CF}$ among other factors and therefore is not reliable for lesion depth assessment. However, EI control is still important to detect potentially life-threatening phenomena, such as coagulum formation and vaporization [4]. The simplicity of the proposed catheter design simplifies the integration of US imaging with additional sensors.

\section{Thermal mechanisms in TEI: tissue deformation and speed of sound variations}

Finally, the thermal mechanisms involved in the strain plots of Figs. 3 and 7 are qualitatively discussed. The speed of sound (SOS) measurements in homogeneously heated tissue show an increase with temperature $\mathrm{T}$ of $\sim 45 \mathrm{~m} \mathrm{~s}^{-1}$ from $\mathrm{T}=20^{\circ} \mathrm{C}\left(1623 \mathrm{~m} \mathrm{~s}^{-1}\right)$ up to $55^{\circ} \mathrm{C}$, where a slope change is observed indicating tissue denaturation. This is in agreement with previous observations in muscle tissue $[34,43,44]$. A similar trend is observed in water; however, the slope change occurs at different temperatures $\left(\sim 75^{\circ} \mathrm{C}\right)$. Accordingly, if SOS variations would be the main effect in the strain images, an apparent negative instantaneous strain (SOS increase) should be observed at the beginning of ablation, followed by a positive strain for $T>55^{\circ} \mathrm{C}$ (SOS decrease). Observing Fig. 3d, however, a positive strain band (1) is observed close to the catheter during ablation $(t>20 \mathrm{~s})$, which progresses according to the visually observed lesion size. This band is followed in depth by a negative strain region (2) that levels off with (1). We believe that (1) is associated to the thermal expansion of the coagulating tissue, similarly to the hypothesis of [35] for HIFU ablated liver tissue. Since the catheter/patch electrode distance is kept constant, 


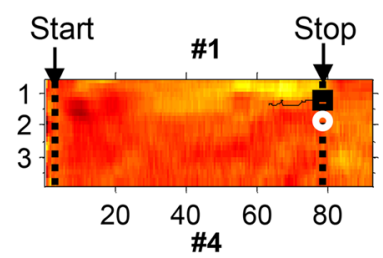

\section{TEl-scan}
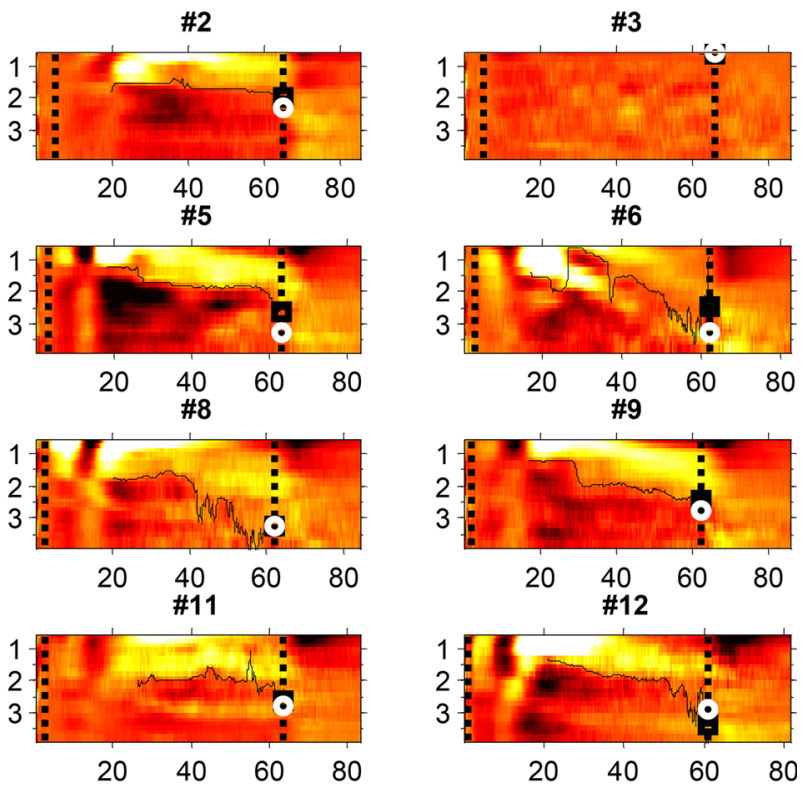

Instantaneous

strain (a.u.)

$\square .05$

$-0.05$

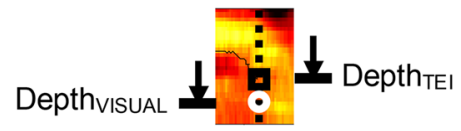

Fig. 7 TEI images for the experiments of Fig. 5. The identified thermal expansion boundary is plotted on the images, together with the visually identified and US estimated ablation depths

the thermally expanding tissue pushes the adjacent tissue layers, so that negative strains are observed. Consequently, the zero-crossing between both positive and negative strains effectively represents the ablation boundary.

This hypothesis is further supported by effective SOS measurement during ablation across the $10 \mathrm{~mm}$ thick tissue sample \#5, based on the reflected echo at the patch electrode (Fig. 9). Since tissue strains are leveraged with the fixed US sensor/reflector distance, the measured time of flight variations is exclusively due to SOS changes in tissue. A monotonic increase in SOS with ablation time is observed in the tissue heating phase up to $20 \mathrm{~s}$, upon which the RFA ablation leads to a plateau and change of slope sign in the SOS curve, indicating the beginning of ablation. This agrees very well with the observations of [34], who used the change of SOS slope as an indication of the start of tissue necrosis. Upon ablation termination $(t>60 \mathrm{~s})$, a SOS increase is observed, which may be associated with a permanent increase in stiffness in the necrotic tissue [30], and which eventually leverages with the SOS decrease due to the cooling down of non-ablated tissue. Further investigation is required to clarify this effect, together with the apparent tissue expansion and compression cycle observed close to the catheter in the transient period $(t<20 \mathrm{~s})$ preceding ablation (Figs. 3d, 7).

\section{Conclusions and outlook}

The feasibility of TEI imaging for automatic real-time lesion depth assessment based on a single US sensor has been proven with in vitro experiments. The experiments show that TEI is highly robust to $\mathrm{CF}$, to ablation time, and even to tissue heterogeneity to large extent. The discontinuous progression of an ablated front through heterogeneous tissue makes such a direct lesion depth assessment necessary to monitor lesion depth during RFA. The method shows a high potential for in vivo lesion depth and transmurality assessment. Imaging myocardial tissue in function of depth, it is expected to be insensitive to catheter-tissue contact surface and cavitary blood flow. Moreover, the integrated US sensor follows the actual direction of ablation, compensating for catheter misalignments. The TEI method is decoupled from the ablation parameters used and is complementary to other control measurements, such as electrical impedance (EI) and contact force $(\mathrm{CF})$. The simplicity of the proposed catheter design simplifies the integration of US imaging with additional sensors.

Our study confirms that the information of the ablation front is coded in the phase of the US time series, while M-mode intensity images do not provide a reliable assessment of RFA lesions. The TEB seems to be associated to a 

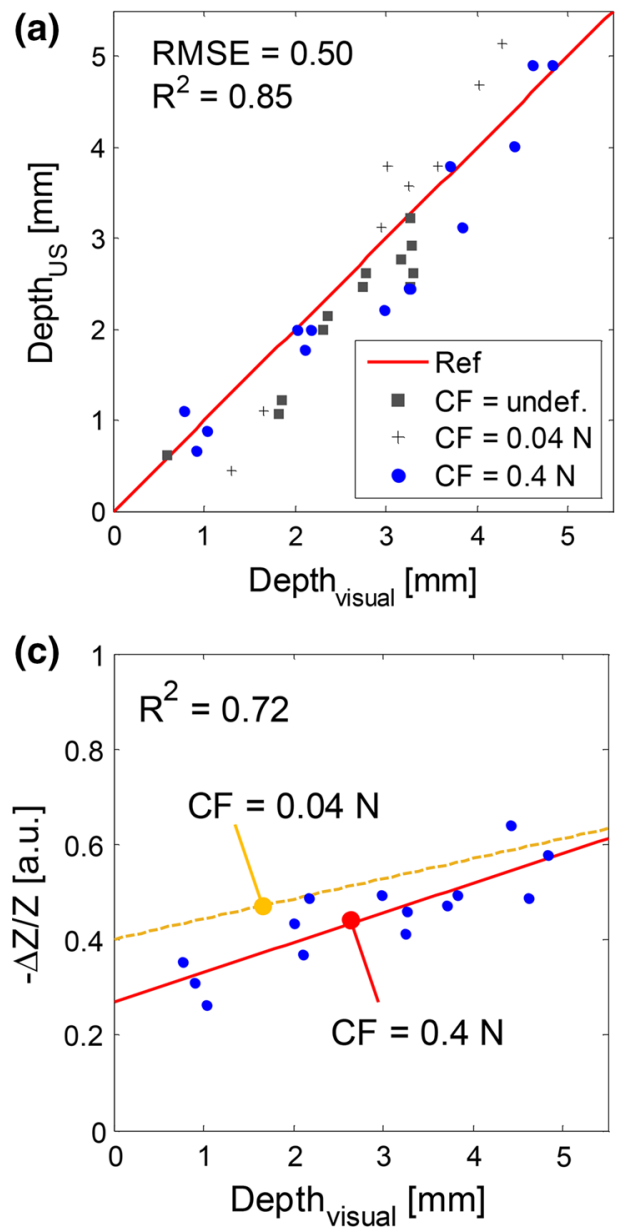

Fig. 8 Regression between measured variables. a US estimated

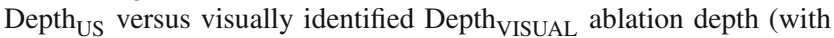
undefined contact force $\mathrm{CF}$-data of Fig. 6 and with $\mathrm{CF}=0.04 \mathrm{~N}$ and $\mathrm{CF}=0.4 \mathrm{~N}$ ). $\mathbf{b}$ Lesion depth for given ablation duration with $\mathrm{CF}=0.4 \mathrm{~N}$. c Electrical impedance (EI) magnitude decrement $\Delta \mathrm{Z} / \mathrm{Z}$. d EI phase

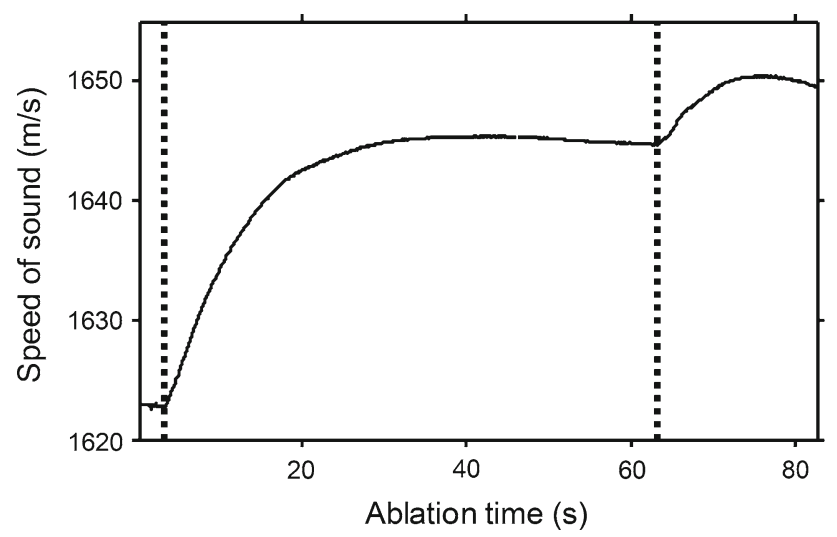

Fig. 9 Effective SOS for the RFA experiment of Fig. 3 (sample \#5 in Figs. 5, 6 and 7), based on echo reflection at the patch electrode plate

structural modification of the tissue upon coagulation rather than a SOS change. The spatially adjacent positive and negative strain bands strongly suggest thermal expansion as the
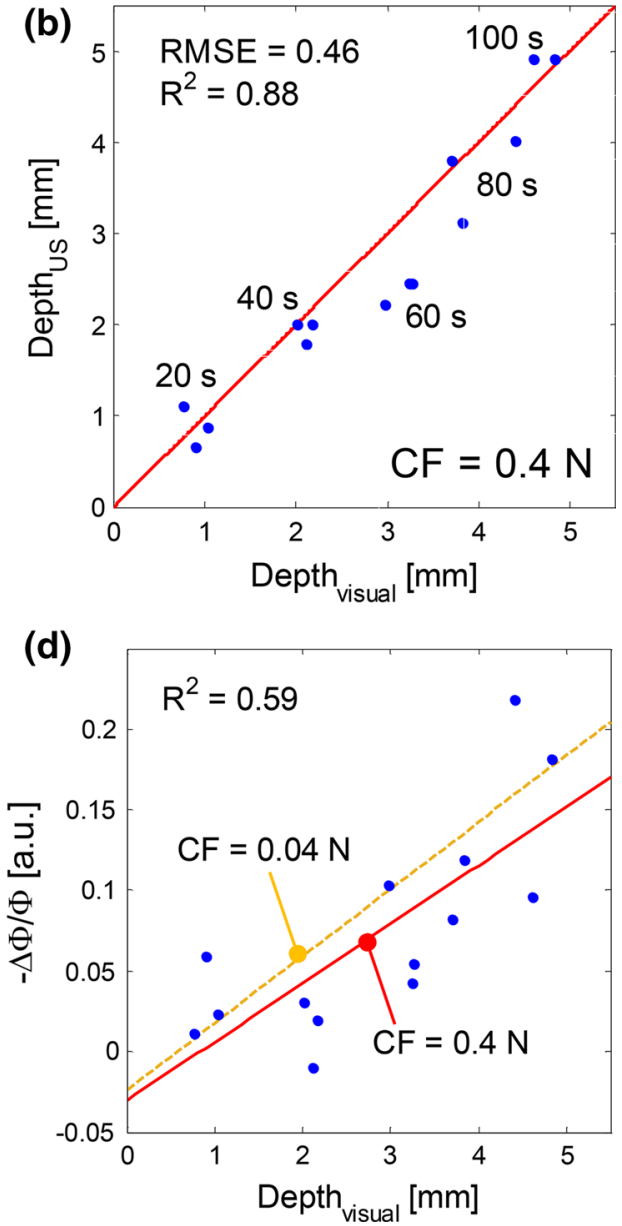

decrement- $\Delta \Phi / \Phi$. In (a) and (b), the root-mean-square error (RMSE) and the coefficient of determination $\left(R^{2}\right)$ were calculated with respect to the identity relation Depth $\mathrm{US}_{\mathrm{US}}=$ Depth $_{\mathrm{VISUAL}}$. For $(\mathbf{c})$ and $(\mathbf{d}) R^{2}$ correspond to the linear least squares fit for $\mathrm{CF}=0.4 \mathrm{~N}$, the regression line for $\mathrm{CF}=0.04 \mathrm{~N}$ is as well plotted for comparison

main strain mechanism during coagulation, accompanied by compression of the adjacent non-ablated tissue. Monitoring the effective SOS in tissue with a fixed reflector reveals a monotonic SOS increase up to coagulation, thereafter followed by a SOS plateau. The strain mechanisms in the transient period between RFA start and tissue coagulation should be further investigated.

There is still potential for improvement of the zerocrossing-based TEI tracking, by leveraging additional information in the smoothly expanding nature and monotonically expanding nature of the ablation lesions for temporal consistency of the identified TEB. The isolation of thermal-induced displacements from in vivo motion is also a matter of future research. Similarly, although qualitative relations have been observed between tissue heterogeneity and the time evolution of the TEB, a quantitative analysis for well-defined heterogeneous tissue layers is still required. The described TEI imaging method is generic and can be potentially applied 
in catheter-based ablation treatment of tumors [45], as well as to percutaneous RF ablation (e.g., of liver [46]) and to high-intensity focused ultrasound (HIFU).

Acknowledgments This work was supported by the Swiss National Science Foundation (SNSF).

Conflict of interest Peter Baki, Sergio J. Sanabria, Gabor Kosa, Gabor Szekely and Orcun Goksel declare that they have no conflict of interest.

\section{References}

1. De Luna AB (2012) Clinical electrocardiography: a textbook. Wiley, Chichester, UK

2. Kannel WB, Abbot RD, Savage DD, McNamara PM (1982) Epidemiologic features of chronic atrial fibrillation: the framingham study. N Engl J Med 306(17):1018-1022

3. Ostrander L, Brandt RL, Kjelsberg MO, Epstein FH (1965) Electrocardiographic findings among the adult population of a total natural community, tecumseh, michigan. Circulation 31(6):888-898

4. McRury ID, Haines DE (1996) Ablation for the treatment of arrhythmias. Proc IEEE 84(3):404-416

5. Haissaguerre M, Jais P, Shah DC (1998) Spontaneous initiatoin of atrial fibrillation by ectopic beats originating in the pulmonary veins. N Engl J Med 339:659-666

6. Haines DE (1993) The biophysics of radiofrequency catheter ablation in the heart: the importance of temperature monitoring. Pacing Clin Electrophysiol 16(3):586-591

7. Nath S, Lynch C, Whayne JG, Haines DE (1993) Cellular electrophysiological effects of hyperthermia on isolated guinea pig papillary muscle. Implications for catheter ablation. Circulation 88(4):1826-1831

8. Matsudaira K, Nakagawa H, Wittkampf FH, Yamanashi WS, Imai S, Pitha JV, Lazzara R, Jackman WM (2003) High incidence of thrombus formation without impedance rise during radiofrequency ablation using electrode temperature control. Pacing Clin Electrophysiol 26(5):1227-1237

9. Cappato R, Calkins H, Chen S-A (2010) Updated worldwide survey on the methods, efficacy, and safety of catheter ablation for human atrial fibrillation. Circ Arrhythm Electrophsiol 3:32-38

10. Shah D (2011) A critical appraisal of cardiac ablation technology for catheter-based treatment of atrial fibrillation. Expert Rev Med Devices 8(1):49-55

11. Haemmerich D (2010) Biophysics of radiofrequency ablation. Crit Rev Biomed Eng 38(1):53-63

12. Perez FJ, Wood MA, Schubert CM (2006) Effects of gap geometry on conduction through discontinuous radiofrequency lesions. Circulation 113:1723-1729

13. Okumura Y, Johnson SB, Bunch TJ, Henz BD, O'Brien CJ, Packer DL (2008) A systematical analysis of in vivo contact forces on virtual catheter tip/tissue surface contact during cardiac mapping and intervention. J Cardiovasc Electrophysiol 19(6):632-640

14. Blouin LT, Marcus FI, Lampe L (1991) Assessment of effects of a radiofrequency energy field and thermistor location in an electrode catheter on the accuracy of temperature measurement. Pacing Clin Electrophysiol 14(5):807-813

15. Chugh SS, Chan RC, Johnson SB, Packer DL (1999) Catheter tip orientation affects radiofrequency ablation lesion size in the canine left ventricle. Pacing Clin Electrophysiol 22(3):413-420

16. Lustgarten DL, Spector PS (2008) Ablation using irrigated radiofrequency: a hands-on guide. Heart Rythm 5(6):899-902

17. Shah DC, Lambert H, Nakagawa H, Lagenkamp A, Aeby N, Leo G (2010) Area under the real-time contact force curve (force-time integral) predicts radiofrequency lesion size in an in vitro contractile model. J Cardiovasc Electrophysiol 21(9):1038-1043

18. Yokoyama K, Nakagawa H, Shah DC, Lambert H, Giovanni L, Aeby N, Ikeda A, Pitha JV, Sharma T, Lazzara R, Jackman WM (2008) Novel contact force sensor incorporated in irrigated radiofrequency ablation catheter predicts lesion size and incidence of steam pop and thrombus/clinical perspective. Circ Arrhythm Electrophsiol 1(5):354-362

19. Betensky BP, Jauregui M, Campos B, Michele J, Marchlinski FE, Oley L, Wylie B, Robinson D, Gerstenfeld EP (2012) Use of a novel endoscopic catheter for direct visualization and ablation in an ovine model of chronic myocardial infarction. Circulation 126:20652072

20. Kolandaivelu A, Zviman MM, Castro V, Lardo AC, Berger RD, Halperin HR (2010) Non-invasive assessment of tissue heating during cardiac radiofrequency ablation using MRI thermography/clinical perspective. Circ Arrhythm Electrophsiol 3:521-529

21. Ranjan R, Koholmovski EG, Blauer J (2012) Identification and acute targeting of gaps in atrial ablation lesion sets using a real-time magnetic resonance imaging system. Circ Arrhythm Electrophsiol 5:1130-1135

22. Hoskins P, Martin K, Thrush A (2010) Diagnostic ultrasound: physics and equipment. Cambridge University Press, New York

23. Bush N, Rivens I, Ter Haar G, Bamber J (1993) Acoustic properties of lesions generated with an ultrasound therapy system. Ultrasound Med Biol 19(9):789-801

24. Hynynen K (1997) Review of ultrasound therapy. In: Proceedings IEEE ultrasonics symposium, pp 1305-1313

25. Maleke C, Konofagou EE (2008) Harmonic motion imaging for focused ultrasound: a fully integrated technique for sonification and monitoring of thermal ablation in tissues. Phys Med Biol 53(6):1773-1793

26. ter Haar G, Sinnett D, Rivens I (1995) Ultasound focal beam surgery. Ultrasound Med Biol 21(9):1089-1100

27. Kumon RE, Gudur MS, Zhou Y, Deng CX (2012) High-frequency ultrasound M-mode imaging for identifying lesion and bubble activity during high-intensity focused ultrasound ablation. Ultrasound Med Biol 38(4):626-641

28. Bunch TJ, Bruce GK, Johnson SB, Sarabanda A, Milton MA, Packer DL (2004) Analysis of catheter-tip (8-mm) and actual tissue temperatures achieved during radiofrequency ablation at the orifice of the pulmonary vein. Circulation 110(19):2988-2995

29. Wright M, Harks E, Deladi S, Suijver F, Barley M, van Dusschoten A, Fokkenrood S, Zuo F, Sacher F, Hocini M, Haïssaguerre M, Jäis P (2011) Real-time lesion assessment using a novel combined ultrasound and radiofrequency ablation catheter. Heart Rythm 8(2):304-312

30. Eyerly SA, Hsu SJ, Agashe SH, Trahey GE, Li Y, Wolf PD (2010) An in vitro assessment of acoustic radiation force impulse imaging for visualizing cardiac radiofrequency ablation lesions. J Cardiovasc Electrophysiol 21(5):557-563

31. Seo CH, Shi Y, Huang SW, Kim K, O'Donnell M (2011) Thermal strain imaging: a review. Interface Focus 1(4):649-664

32. Miller NR, Bamber JC, Ter Haar G (2004) Imaging of temperatureinduced echo strain: preliminary in vitro study to assess feasibility for guiding focused ultrasound surgery. Ultrasound Med Biol 30(3):345-356

33. Varghese T, Zagzebski JA, Chen Q, Techavipoo U, Frank G, Johnson C, Wright A, Lee FT Jr (2002) Ultrasound monitoring of temperature change during radiofrequency ablation: preliminary in-vivo results. Ultrasound Med Biol 28(3):321-329

34. Seo CH, Stephens D, Cannata J, Dentinger A, Lin F, Park S, Wildes D, Thomenius KE, Chen P, Nguyen T, de La Rama A, Jeong JS, Mahajan A, Shivkumar K, Nikoozadeh A, Oralkan O, Truong U, Sahn DJ, Khuri-Yakub PT, O’Donnell M (2011) The feasibility of using thermal strain imaging to regulate energy delivery during 
intracardiac radio-frequency ablation. IEEE Trans Ultrason Ferroelectr Freq Control 58(7):1406-1417

35. Souchon R, Bouchoux G, Maciejko E, Lafon C, Cathignol D, Bertrand M, Chapelon JY (2005) Monitoring the formation of thermal lesions with heat-induced echo-strain imaging: a feasibility study. Ultrasound Med Biol 31(2):251-259

36. Baki PS (2014) Sensorized cardiac radiofrequency ablation system for lesion depth assessment. PhD Thesis, ETH Zurich

37. Baki PS, Szekely G, Kosa G (2013) Design and characterization of a novel, robust, tri-axial force sensor. Sensor Actuat A Phys 192:101-110

38. Cao H, Tungjitkusolmun S, Choi YB, Tsai J, Vorperian VR, Webster JG (2002) Using electrical impedance to predict catheterendocardial contact during rf cardiac ablation. IEEE Trans Biomed Eng 49(3):247-253

39. Wittkampf FH, Hauer RN, de Medina ER (1989) Control of radiofrequency lesion size by power regulation. Circulation 80(4):962-968

40. Stephens DN, O'Donnell M, Thomenius K, Dentinger A, Wildes D, Chen P, Shung KK, Cannata J, Khuri-Yakub P, Oralkan O, Mahajan A, Shivkumar K, Sahn DJ (2009) Experimental studies with a 9 f forward-looking intracardiac imaging and ablation catheter. $\mathbf{J}$ Ultrasound Med 28(2):207-215
41. Kallel F, Ophir J (1997) A least-squares strain estimator for elastography. Ultrasonic Imaging 19:195-208

42. Khurana I (2009) Textbook of medical physiology. Elsevier, Delhi

43. Lu J, Ying H, Sun Z, Motamedi M, Bell B, Sheppard L C (1996) In vitro measurement of speed of sound during coagulate tissue heating. In: Proceedings IEEE ultrasonics symposium, pp 1299 1302

44. Masugata H, Mizushige K, Senda S, Kinoshita A, Sakamoto H, Sakamoto S, Matsuo H (1999) Relationship between myocardial tissue density measured by microgravimetry and sound speed measured by acoustic microscopy. Ultrasound Med Biol 25(9):14591463

45. van Sonnenberg E, Livraghi T, Mueller PR, McMuller W, Golbiati L, Silverman SG (2008) Tumor ablation: principles and practice. Springer, New York

46. Livraghi T, Goldberg SN, Lazzaroni S, Meloni F, Solbiati L, Gazelle GS (1999) Small hepatocellular carcinoma: treatment with radio-frequency ablation versus ethanol injection. Radiology 210:655-661 